\title{
La interpretación de datos y pruebas científicas vistas desde los ítems liberados de PISA
}

\author{
Javier Muñoz ${ }^{1, a}$, Elena Charro ${ }^{2, b}$ \\ ${ }^{1,2}$ Departamento de Didáctica de las Ciencias Experimentales y de la Matemática, Universidad de \\ Valladolid. Valladolid. España. \\ ajaviermmweb@gmail.com; ${ }^{b}$ echarro@dce.uva.es
}

[Recibido: 29 junio 2017. Revisado: 29 agosto 2017. Aceptado: 8 noviembre 2017]

Resumen: La Competencia Científica evaluada por las pruebas PISA requiere la confluencia entre los tipos de conocimiento y las subcompetencias evaluadas en ellas, a fin de analizar cómo están capacitados los estudiantes para aportar efectivamente a la sociedad. De esta manera, los resultados de esta prueba trienal pueden dar cuenta del desarrollo de un determinado país. Por tal motivo, son necesarios estudios que profundicen en cada subcompetencia y clarifiquen sus componentes, y que presenten sus fundamentos teóricos con gran cantidad de ejemplos, para así facilitar su comprensión a los docentes. Para este fin, y mediado por análisis de contenido, se revisaron 164 ítems liberados por PISA, siendo caracterizados y categorizados según las habilidades específicas que evalúan y los tipos de conocimiento que utilizan. En este estudio, a partir de los ítems liberados, se analiza la subcompetencia Interpretar datos y pruebas cientificamente, encontrándose que da especial importancia a la habilidad del estudiante para utilizar las formas más comunes de abstracción y presentación de datos, así como para usar los conocimientos de contenido procedimental y epistémico, y, en consecuencia, para generar o elegir la conclusión más adecuada. Este trabajo pretende ser una guía para el docente, ya que pone a su disposición información detallada y relevante, sobre las características que deben tener tablas, gráficas, figuras y texto para construir, leer, analizar e interpretar los datos apropiadamente y, en consecuencia, ser una herramienta de evaluación diagnóstica, donde visibilizar las debilidades de los estudiantes y plantear mejoras en las intervenciones en el aula.

Palabras clave: Ítems PISA, Conocimientos y habilidades científicas, Competencia científica, uso de pruebas.

\section{The Interpretation of data and scientific evidence seen from the released items of PISA}

Abtsract: The Scientific Competence is evaluated by the PISA tests, and for that, it requires the confluence between the different types of knowledge and the subcompetences evaluated through them, in order to know the grade of qualification of the students for contributing effectively to society. Thus, the results of this three-year test can show the development of a specific country. For this reason, studies which analyse each subcompetence and clarify its components, and show their theoretical foundations with a large number of examples, are needed for teachers. For this purpose, 164 items released by PISA were reviewed using content analysis, characterized and categorized according to the specific skills they assess and the types of knowledge they use. As a part of that, in this study, the subcompetence Interpreting scientifically data and evidences is analyzed from the released items, finding that it gives special importance to the student's ability to use the most common forms of abstraction and presentation of data, as well as to use the knowledge of content, procedural and epistemic to generate or choose the most appropriate conclusion. This study aims to be a guide for the teacher, since it provides detailed and relevant information about the characteristics of tables, graphs, figures and text in order to build, read, analyze and understand the data properly, and also be a tool for a diagnostic evaluation, and let to visualize the deficiencies in the student knowledge's and to improve the interventions in the classroom.

Keywords: PISA items; Scientific knowledge and skills; Scientific Competences; use of evidences.

Para citar este artículo: Muñoz J. y Charro E. (2018) La Interpretación de Datos y Pruebas Científicas vistas desde los Ítems liberados de PISA. Revista Eureka sobre Enseñanza y Divulgación de las Ciencias 15(2), 2101. doi: 10.25267/Rev_Eureka_ensen_divulg_cienc.2018.v15.i2.2101

\section{Introducción}

Las pruebas internacionales PISA (Programa Internacional para la Evaluación de Alumnos), es el proyecto a cargo de la OECD (Organización para la Cooperación y Desarrollo 
Económicos), que se centra en evaluar a estudiantes de 15 años de edad de más de 70 países del mundo, con el fin de generar indicadores de rendimiento que permitan definir políticas de largo alcance a partir de las debilidades y fortalezas de los sistemas educativos de los países participantes. Estas pruebas tuvieron sus inicios en el año 2000 y se ejecutan con una regularidad trienual; a la fecha se han presentado seis versiones, donde cada una ha sufrido mejoras, con el fin de presentar resultados satisfactorios que expliquen la realidad de un país en torno al proceso educativo. Sin embargo, el ranking resultante solo da una idea superficial de la realidad educativa en cada nación a partir de la gran cantidad de datos que la OECD pone a disposición del público, sin llegar a profundizar en todos los aspectos que pueden obtenerse.

PISA 2015 publica todos los datos en su página oficial (OECD 2017). De los resultados generados por subescalas, se pueden extraer las tablas en torno a cada una de las subcompetencias que componen la Competencia Científica, mostrando que, por ejemplo, en esa fecha no todos los países tienen las mismas debilidades. Países como Australia, Canadá, Dinamarca, Finlandia, e Irlanda, entre otros, presentan bajos puntajes en la subcompetencia Interpretar datos y pruebas científicamente. Otros, como Austria, Chile, República Checa, Alemania, Japón, Italia y España, los presentan en la subcompetencia Evaluar y diseñar la Investigación científica; y Bélgica, Corea, México, Portugal, entre otros, lo hacen en la subcompetencia: Explicar fenómenos cientificamente. Por tanto, es necesario dejar de ver la Competencia Científica como un todo, y analizarla según las subcompetencias que la componen.

Pero ¿qué aborda cada una de estas subcompetencias? Este ha sido el interrogante que ha dado origen a esta investigación. Para resolverlo, fue necesario revisar cada uno de los marcos teóricos publicados por PISA y las diferentes fuentes, para generar una gran base de ítems liberados que facilitaran su comprensión.

La primera subcompetencia, Evaluar y Diseñar la Investigación Científica, ha sido analizada y categorizada por Muñoz y Charro (2017), dejando ver a través de los ítem analizados, la importancia dada a los siguientes aspectos: desarrollo de habilidades como la identificación de la pregunta de investigación; distinción entre lo que es científico y lo que no; identificación de variables dependientes e independientes en una indagación científica; reconocimiento de información adicional que aporte a la investigación; métodos de muestreo y recolección de datos; identificación de conceptos en la indagación científica; usos de términos claves; y diseños experimentales apropiados.

En el presente trabajo, se abordará la subcompetencia Interpretar datos y pruebas cientificamente, donde se profundizará en los aspectos teóricos que la fundamentan y los conocimientos que se utilizan (contenido, procedimentales y epistémicos) a través de una variedad de ejemplos, con el objetivo principal centrado en el uso y análisis de las diferentes formas de abstracción de los datos. Esto es el empleo de tablas, gráficas, imágenes y figuras, cuyo manejo y comprensión, en la actualidad, se convierten en una herramienta potencial, no solo en el área de las ciencias, sino también en el entendimiento del mundo, regido por índices presentados en estas formas.

De esta manera, los ítems expuestos como ejemplos en este trabajo, pueden ser utilizados en una evaluación diagnóstica, que permita al docente su uso, como herramienta de retroalimentación de los conocimientos y habilidades específicas, para tener en cuenta en su trabajo con los estudiantes; además, pueden llevar a detectar, de primera mano, cuáles de estas formas de abstracción de los datos son las más complejas para ellos y, por tanto, saber en qué debe profundizar para alcanzar los mejores desempeños con sus alumnos. 


\section{Interpretar datos y pruebas científicas}

Un cuerpo de conocimientos procedimentales importante, tenido en cuenta por las pruebas PISA, subyace de una corriente nombrada como alfabetización gráfica (Postigo y Pozo 2000), la cual se centra en generar conocimientos y capacidades en los estudiantes, en relación con las gráficas y análisis de los datos, considerándose estos conocimientos y habilidades esenciales para la plena participación en las sociedades modernas (OECD 2016), ya que los estudiantes deben estar preparados para los desafíos a los que les enfrenta la Humanidad -como la provisión de agua y alimentos, el control de enfermedades, la generación de energía y adaptación al cambio climático (UNEP 2012)-.

La alfabetización gráfica y el análisis e interpretación adecuada de los datos otorgan ventaja en la búsqueda de patrones y en la construcción de tablas y gráficos, así como en el análisis e interpretación de los estos, dándoles significado, puesto que estos no hablan por sí mismos (National Research Council 2012). También, en la obtención de conclusiones a partir de pruebas válidas y confiables que lleven a los estudiantes a tomar decisiones en la solución de un problema específico, potenciando, así, el desarrollo de su región o país.

La alfabetización gráfica ha tomado gran importancia en el trabajo con los estudiantes, generando investigaciones como la de Berciano et al. (2015). Al evaluar el desempeño de interpolación/extrapolación gráfica en matemáticas con estudiantes de bachillerato de ciencias sociales, estos autores reconocen su importancia como propuesta didáctica y complementaria al método algebraico, ya que, con las instrucciones adecuadas, facilita el proceso de comprensión e interpretación de las funciones trabajadas. Así mismo, Solar et al. (2015) se centrraron en trabajar el proceso de modelización de las gráficas y su posterior interpretación, generando unidades didácticas basadas en tres etapas: 1) identificar sistemas de referencia, construir sistemas de referencia, 2) identificar variables, estudiar dependencia entre variables; y, 3) traducir representaciones, interpretar gráficas, encontrando que los alumnos, a lo largo de la etapa escolar, tienden a obtener mejores resultados cuando hacen los procesos de interpretación, a partir del modelo gráfico construido de la expresión algebraica dada.

Desde las ciencias, Perales et al. (2015) introducen a los estudiantes a un proceso de investigación a partir del análisis de imágenes de los libros de ciencias, encontrando que, cuando aquellos hacen un proceso de observación del objeto, figura, imagen o gráfica, son capaces de describir y ejemplificar lo que representa dicho objeto, extrayendo información de él y relacionándola con el texto acompañante. Sin embargo, a pesar de que los textos tienen gran cantidad de imágenes, los alumnos no siempre las utilizan de modo autónomo, siendo necesarias las indicaciones del docente al uso y análisis de este tipo de representaciones de la información. (Perales y Vilchez 2015).

Al profundizar en el concepto de alfabetización gráfica, encontramos que comprende dos aspectos importantes necesarios, que deben ponerse en práctica álgidamente en los colegios: por un lado, la elaboración o construcción de tablas o gráficos; y, por otro, la interpretación de los datos que se han representado en estas formas de abstracción (Baquero et al. 2000).

PISA ha enfocado su proceso de evaluación en el segundo aspecto de la alfabetización gráfica: Interpretar datos y pruebas cientificas (OECD 2016), donde el punto principal son los datos, las pruebas científicas y la capacidad del estudiante para interpretarlas y generar conclusiones a partir de ellas o evaluar la que mejor se ajusta. Por ello, es importante tener claro qué es una prueba, entendida esta como una observación, un hecho, un experimento, una señal, una muestra o una razón, que puede ser tanto empírica como teórica (Bravo et al. 2009). Estas pruebas y datos científicos son presentados en las formas más comunes de abstracción y 
representación: descripciones textuales, gráficos, tablas, diagramas, figuras o imágenes (Gott y Duggan 1996, Postigo y Pozo 2000, Schalk et al. 2008, Osborne 2013 y OECD 2016).

La interpretación de datos representados gráficamente requiere diferentes niveles de lectura y comprensión de la información, donde el nivel más elemental es el de lectura literal del gráfico, tabla o texto, identificando los elementos básicos como el número y tipo de variables representadas, su correspondencia con los valores asignados y la identificación o asignación del título. Aquí no hay un proceso de interpretación de la información, ya que los datos se pueden calcular o deducir directamente. Leinhardt, et al. (1990), Carswell et al. (1993) y Swan y Philips (1998) se refieren a este nivel como la capacidad de identificar la información local; en cambio, Curcio (1989) lo designa como el nivel de leer entre los datos, y Postigo y Pozo (2000) lo toman como el nivel explícito de la comprensión de la información.

El segundo nivel precisa un proceso de interpretación de los datos, puesto que deben analizarse globalmente con el fin de cumplir tareas como la comparación de datos, la identificación de la relación entre variables, la identificación de patrones y tendencias que siguen los datos y el reconocimiento de convenciones. Este segundo nivel se complementa con lo propuesto por Leinhardt et al. (1990), Carswell et al. (1993) y Swan y Philips (1998), que se refieren a él como la capacidad de identificar la información global; Curcio (1989), quien lo designa como el nivel de leer dentro de los datos; y, Postigo y Pozo (2000), que se refieren a él como el nivel implícito de la comprensión de la información.

El tercer nivel exige la elaboración de conclusiones, explicaciones y predicciones o inferencias, a partir de la información que aportan los datos, representados en las gráficas o tablas, donde también es preciso un análisis global de la información (Leinhardt et al. 1990, Carswell et al. 1993 y Swan y Phillips 1998) o una lectura más allá de los datos según Curcio (1989), que coincide también con el nivel conceptual de la compresión de la información, según Postigo y Pozo (2000). Estos últimos sustentan que el nivel conceptual se basa, en buena medida, en los dos anteriores y busca relaciones conceptuales a partir del análisis global de la gráfica y de la relación con el contexto, presentado con el fin de generar diferentes niveles de procesos: conclusiones, explicaciones y predicciones del fenómeno presentado.

Un cuarto nivel, según Friel et al. (2001), corresponde a la lectura de la información analizando críticamente los datos, teniendo en cuenta su calidad, validez y fiabilidad, según el método empleado para la recogida de estos, que permitan generar explicaciones adicionales y elaborar nuevos modelos.

Teniendo en cuenta lo anterior, la estructura de los ítems PISA que analizan la competencia Interpretar datos y pruebas cientificas se basa en un nivel de interpretación conceptual en los términos de Postigo y Pozo (2000), ya que el análisis de la relación de las pruebas o los datos con el contexto dado juegan un papel muy importante a la hora de seleccionar o generar la mejor conclusión, explicación, predicción o evaluación de las opciones presentadas.

Smith et al. (2010) también utilizan el nivel conceptual como el más alto de su categorización, teniendo en cuenta el tipo de preguntas habituales en ciencias, donde el análisis e interpretación de los datos presentados en tablas o gráficos son parte de este nivel. Al tratarse de una investigación en un contexto de la vida real, lleva al estudiante a combinar las formas de pensar y entender los aspectos científicos del mundo, lo que también permite evaluar el nivel conceptual y procedimental de alfabetización científica alcanzado, según lo propuesto por Bybee (1997) y en el cual se han fundamentado las prueba PISA.

Es precisamente en este nivel conceptual donde los estudiantes presentan mayor dificultad, tal como lo demuestra García y Palacios (2007) al mencionar en su investigación que a los participantes se les dificulta: identificar la relación entre las variables, elaborar conclusiones y 
predecira partir de la información de la gráfica.

Por ello, se abordará la competencia interpretar datos y pruebas científicas desde el punto de vista de los ítems liberados de PISA, analizando sus características y cómo asumen el tercer nivel de lectura y comprensión de la información, es decir, el nivel conceptual en los términos de Postigo y Pozo (2000). Esto con el fin de alcanzar el desarrollo de procesos tan complejos como: la elaboración de conclusiones, explicaciones y predicciones o inferencias, a partir de la información que aportan los datos representados en las gráficas o tablas, en diferentes contextos.

\section{Metodología}

Esta investigación se inicia con una revisión detallada de los marcos teóricos de PISA 2000 a 2015. En primer lugar, y con el fin de hacer un seguimiento a los procesos y subcompetencias científicas propuestas por la OECD, se definen los grupos de habilidades específicas más relevantes. En segundo lugar, se continúa con la recopilación de 55 unidades PISA de ciencias, que fueron el corpus de análisis para la categorización de las habilidades y conocimientos, en donde, teniendo en cuenta la estructura de los ítems presentada en la figura 1, se hizo una primera clasificación con respecto a las capacidades y los conocimientos evaluados en cada ítem.

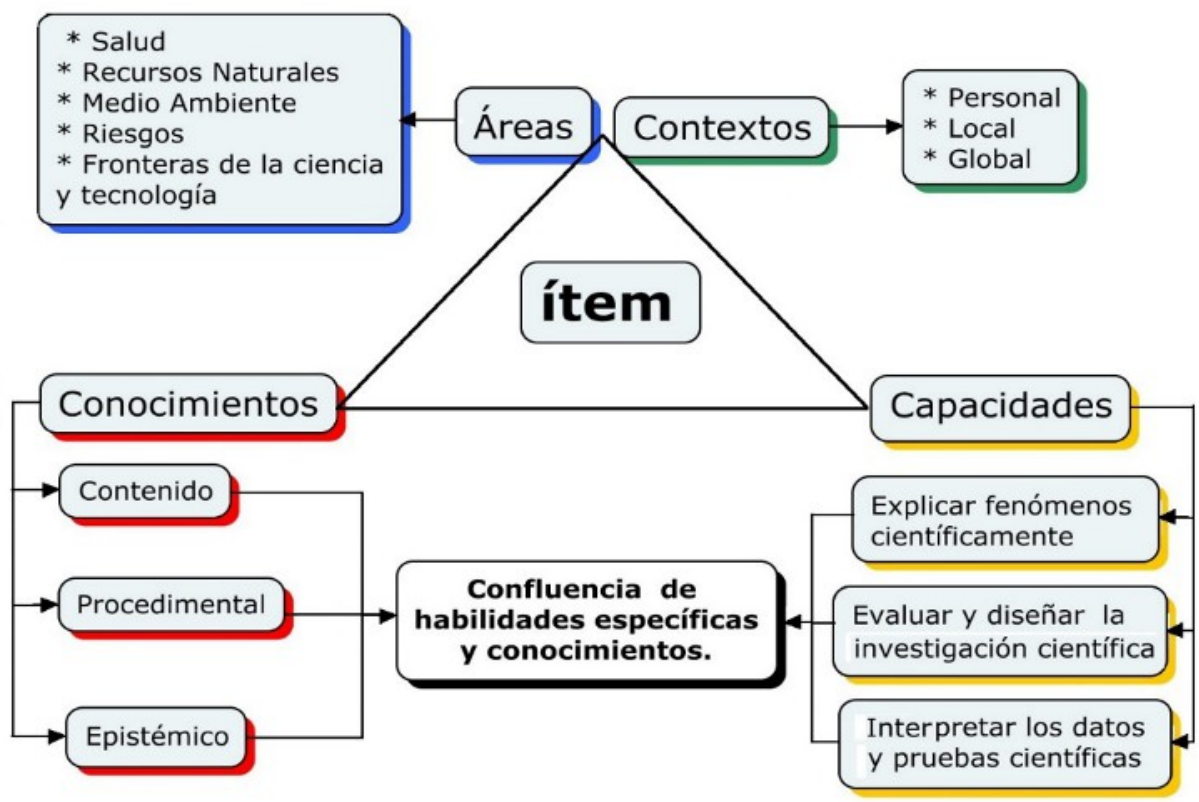

Figura 1. Estructura básica de las dimensiones evaluadas por los ítems PISA de ciencias 2015

Así, en este trabajo se utilizaron 13 unidades pertenecientes a PISA 2000 y 2003; 27 unidades de PISA 2006 y 2009; 10 unidades de PISA 2015; y, 5 unidades extraídas de la página principal de la OECD. Cada unidad tiene un nombre específico y puede contener de 1 a 6 ítems o preguntas, para un total de 164 ítems, los cuales pueden consultarse en el enlace http://revolucioneducativaquimica.blogspot.com.co/. Seguidamente, fueron clasificados de acuerdo con las tres subcompetencias generales de ciencias, propuestas por PISA 2015, utilizando como criterio la información dada en la ficha técnica que acompaña a estos ítems y, finalmente, mediante el uso del análisis de contenido, se categorizó cada ítem, de acuerdo al grupo de habilidades específicas más relevantes propuestas en los marcos teóricos y evaluadas en los ítems, habilidades específicas que no se suelen mencionar en la ficha técnica de los ítems liberados y que se discutirán a continuación. Como ya se mencionó, este trabajo se 
centra en la subcompetencia Interpretar datos y pruebas cientificamente, presentándose 52 ítems que permiten relacionar las habilidades propuestas con los conocimientos utilizados.

El instrumento de evaluación utilizado se presenta en la tabla 1 y permitió la clasificación de acuerdo a varios de los componentes del ítem; en este se muestra un ejemplo -Chocolate-2-, el cual se presenta en el Anexo A.

Tabla 1. Categorías de clasificación y análisis de los ítems liberados de PISA

\begin{tabular}{|c|c|c|c|c|}
\hline Competencia & $\begin{array}{l}\text { Habilidad Específica de interpretar } \\
\text { según la forma de presentación de los } \\
\text { datos }\end{array}$ & $\begin{array}{l}\text { Tipo de } \\
\text { Conocimiento }\end{array}$ & $\begin{array}{l}\text { Nombre del } \\
\text { ítem }\end{array}$ & $\begin{array}{l}\text { Formato de } \\
\text { Pregunta }\end{array}$ \\
\hline $\begin{array}{l}\text { Interpretar } \\
\text { datos y } \\
\text { pruebas } \\
\text { científicas }\end{array}$ & $\begin{array}{l}\text { Interpretar datos dados en forma de } \\
\text { tabla para demostrar una conclusión } \\
\text { dada. } \\
\text { Al utilizar los datos para reafirmar o } \\
\text { dar razones a favor de que "es difícil } \\
\text { que Jessica mantenga su peso con esta } \\
\text { dieta", siendo necesario identificar los } \\
\text { datos correctos para hacer el cálculo } \\
\text { adecuado que justifique que la dieta es } \\
\text { excesiva y no se mantendrá el peso de } \\
\text { la chica. }\end{array}$ & $\begin{array}{l}\text { Conocimiento de } \\
\text { contenido. } \\
\text { Centrado en el uso } \\
\text { de ecuaciones y } \\
\text { cálculos para hacer } \\
\text { las operaciones } \\
\text { adecuadas que } \\
\text { lleven a } \\
\text { argumentar la } \\
\text { respuesta. }\end{array}$ & Chocolate-2 & $\begin{array}{l}\text { Abierta } \\
\text { Que lleva a } \\
\text { la } \\
\text { producción } \\
\text { de } \\
\text { argumentos } \\
\text { o razones } \\
\text { que permitan } \\
\text { defender una } \\
\text { idea. }\end{array}$ \\
\hline
\end{tabular}

No obstante, en la categorización hecha por Muñoz y Charro (2017) en el análisis de la subcompetencia Evaluar y diseñar la investigación científica, las habilidades específicas se presentan de manera más concreta en los ítems. De esta manera, se generan las siguientes categorías: identificar la pregunta de investigación, distinguir entre cuestiones científicas o no, identificar las variables de análisis, reconocer información adicional, identificar medidas para recolección de datos, identificar conceptos del proceso de investigación y reconocer palabras claves en la búsqueda de información.

En la subcompetencia que se analiza en este trabajo de interpretar datos y pruebas científicas, las habilidades de proponer y comunicar conclusiones inciden sobre las preguntas de formato abiertas. Asimismo, las de evaluar conclusiones y elegir la que mejor represente a los datos recaen en preguntas de formato de selección múltiple, limitando una categorización más amplia.

Así pues, después de un análisis profundo sobre el marco teórico de PISA 2015 y la bibliografía citada por ellos, se encuentra que la preocupación principal de la subcompetencia Interpretar datos y pruebas cientificas se da alrededor de la dificultad que tienen los estudiantes de interpretar los datos presentados en diferentes formas de representación (Gott y Duggan 1996, Postigo y Pozo 2000, Schalk et al. 2008, Osborne 2013 y OECD 2016) y cómo en unas se presentan mayores dificultades que en otras (Postigo y Pozo 2000 y García y Palacios 2007).

Lo anterior llevó a establecer una lista de 5 categorías, teniendo en cuenta la presentación de los ítems, es decir, la manera en la que se formula la pregunta. Según este examen, se realizó una clasificación con base al uso de tablas (categoría 1), gráficas (categoría 2), figuras/imágenes (categoría 3), texto (categoría 4) y un grupo de ítems no clasificable en las categorías anteriores (categoría 5). Este es un proceso puramente "deductivo".

Partiendo de este análisis previo, procedemos cómo se ha descrito:

1) se asigna cada ítem a cada una de las categorías previamente establecidas mediante un proceso deductivo;

2) el análisis del contenido y de la complejidad de cada uno de los ítems permite realizar una lectura de la competencia con mayor profundidad, y este proceso tiene lugar de modo 
"inductivo"; y,

3) finalmente, la triangulación permite reducir el sesgo que se puede producir en la categorización de los ítems y el análisis pormenorizado de estos. Para ello, los investigadores involucrados en este estudio contrastarán su análisis y se completará la triangulación de la información, haciendo uso de la información aportada por la literatura revisada.

Por consiguiente, el propósito de este trabajo es analizar, en función de los ítems, las diferentes formas de representación de los datos, de tal manera que sirvan de orientación al docente en su proceso de enseñanza-aprendizaje y, más aún, como evaluación diagnóstica que permita ver en cuáles se presentan mayores dificultades.

\section{Resultados y Discusión}

Desde PISA 2000 a PISA 2015, la competencia científica ha cambiado la forma de reagrupar y evaluar sus procesos, de tal manera que, mientras en la evaluación de PISA 2000 se presentaba mucha atención a las habilidades de comunicar conclusiones válidas y diseñar y evaluar conclusiones, desde PISA 2003 se empieza a hacer énfasis en el proceso de interpretación de los datos, para después llegar a la producción de las conclusiones. Finalmente, desde PISA 2006 a PISA 2015, el título de esta subcompetencia se centra, principalmente, en el proceso de interpretar datos y pruebas científicas, tal como se presenta en la tabla 2. (Muñoz et al. 2017)

Tabla 2. Reagrupación y evolución de los procesos y competencias en PISA 2000 a 2015

\begin{tabular}{|c|c|c|c|}
\hline \multicolumn{2}{|c|}{ Procesos } & \multicolumn{2}{|c|}{ Competencias } \\
\hline PISA 2000 & PISA 2003 & PISA 2006, 2009,2012 & PISA 2015 \\
\hline $\begin{array}{c}\text { Reconocer preguntas } \\
\text { científicamente investigables }\end{array}$ & \multirow[b]{2}{*}{$\begin{array}{l}\text { Comprensión de la } \\
\text { investigación científica }\end{array}$} & \multirow[b]{2}{*}{$\begin{array}{c}\text { Identificar cuestiones } \\
\text { científicas }\end{array}$} & \multirow[b]{2}{*}{$\begin{array}{l}\text { Evaluar y diseñar la } \\
\text { investigación científica }\end{array}$} \\
\hline $\begin{array}{c}\text { Identificar las pruebas } \\
\text { necesaria en una investigación } \\
\text { científica }\end{array}$ & & & \\
\hline $\begin{array}{l}\text { Diseñar o evaluar } \\
\text { conclusiones }\end{array}$ & \multirow{2}{*}{$\begin{array}{l}\text { Interpretación de las } \\
\text { pruebas científicas y } \\
\text { conclusiones }\end{array}$} & \multirow{2}{*}{$\begin{array}{l}\text { Utilizar pruebas } \\
\text { científicas }\end{array}$} & \multirow{2}{*}{$\begin{array}{l}\text { Interpretar datos y } \\
\text { pruebas científicas }\end{array}$} \\
\hline $\begin{array}{c}\text { Comunicar conclusiones } \\
\text { válidas } \\
\end{array}$ & & & \\
\hline $\begin{array}{c}\text { Demostrar la comprensión de } \\
\text { los conceptos científicos }\end{array}$ & $\begin{array}{l}\text { Describiendo, explicando } \\
\text { y prediciendo fenómenos } \\
\text { científicos }\end{array}$ & $\begin{array}{l}\text { Explicar fenómenos } \\
\text { científicos }\end{array}$ & $\begin{array}{l}\text { Explicar fenómenos } \\
\text { científicamente }\end{array}$ \\
\hline
\end{tabular}

Las habilidades de producción de conclusiones a partir de los datos, la selección de la conclusión de una lista de alternativas que represente mejor a los mismos, la capacidad de dar razones a favor o en contra de una conclusión dada, o la capacidad de comunicar dichas conclusiones (OECD 2016), dejan de estar a la cabeza de la lista de habilidades en el marco de PISA 2015, y se da mayor relevancia a la habilidad que deben tener los estudiantes de interpretar los datos dados en diferentes formas de representación (en texto, tablas, gráficas, imágenes o figuras). Con esto, se deja claro que el paso previo a la producción, comunicación y evaluación de conclusiones, se inicia con el proceso de interpretación de los datos, en donde es necesario leerlos en los diferentes niveles ya mencionados en el marco teórico, para después poder proponer o elegir una adecuada conclusión.

En este trabajo la subcompetencia Interpretar datos y pruebas científicas será vista desde las formas de cómo se suministran los datos y pruebas científicas, puesto que, de la habilidad de comprender y usar adecuadamente dichas formas, se facilitará el proceso de interpretación que permita generar y comunicar las conclusiones pertinentes. Por tanto, teniendo en cuenta que las pruebas PISA han construido ítems que pretenden evaluar, principalmente, el nivel 
conceptual de la información, según Postigo y Pozo (2000), o el nivel conceptual y procedimental de alfabetización científica, según lo propuesto por Bybee (1997), las categorías de análisis en esta subcompetencia, se reorientaron y se construyeron a partir de la habilidad de interpretar los datos dados, en forma de texto, gráficas, tablas, imágenes o figuras, dejando ver al docente, la importancia de trabajar en el aula con cada una de ellas, y llevando al estudiante al desarrollo de la capacidad de transformar los datos de una representación a otra.

Aunque estos procesos de interpretación de las pruebas y los datos presentados, tanto en forma textual, como en tablas y gráficas requieren de un cuerpo de conocimientos principalmente procedimentales (De Pro 1998 y Nuñez et al. 2009), los ítems que ejemplifican esta subcompetencia, exigen diferentes tipos de conocimiento, según lo propuesto por la OECD (2016), como el de contenido, en los casos en que el proceso de interpretación requieran de los conceptos puntuales, teorías o hechos de la ciencia, el conocimiento procedimental, en los casos que el proceso de interpretación solo requiera la información explicita, implícita o conceptual brindada en el ítem, o finalmente, el conocimiento epistémico en los ítems que requieran explicaciones, que justifiquen los procedimientos científicos utilizados.

Tabla 3. Formas de Abstracción de los datos e ítems de la subcompetencia Interpretar datos y pruebas cientificas.

\begin{tabular}{|c|c|c|}
\hline Formas de abstracción de datos & \multicolumn{2}{|c|}{ Ítems representativos } \\
\hline $\begin{array}{l}\text { 1. Pruebas o datos presentados en for- } \\
\text { ma de tablas }\end{array}$ & $\begin{array}{l}\text { 1. Chocolate-2 } \\
\text { 2. Combustibles fósiles- } 2 \\
\text { 3. Evolución-1 }\end{array}$ & $\begin{array}{l}\text { 4. Brillo de Labios-1 } \\
\text { 5. El maíz-7 } \\
\text { 6. Erupciones volcánicas-3 }\end{array}$ \\
\hline $\begin{array}{l}\text { 2. Pruebas o datos presentados en for- } \\
\text { ma de gráficas de ejes coordenados }\end{array}$ & $\begin{array}{l}\text { 7. El diario de Semmelweis-1 } \\
\text { 8. Erupciones volcánicas-2 } \\
\text { 9. El cambio climático-1 } \\
\text { 10. Combustible fósiles-3 } \\
\text { 11. El efecto invernadero-1 } \\
\text { 12. El efecto invernadero-2 } \\
\text { 13. Fumar-2 }\end{array}$ & $\begin{array}{l}\text { 14. Síndrome de despoblamiento de } \\
\text { colmenas-3 } \\
\text { 15. La caries dental-3 } \\
\text { 16. Comportamiento del espinoso-2 } \\
\text { 17. Comportamiento del espinoso-3 } \\
\text { 18. Cirugía con anestesia-4 } \\
\text { 19. Energía eólica-1 } \\
\text { 20. Energía eólica-2 }\end{array}$ \\
\hline $\begin{array}{l}\text { 3. Pruebas o datos presentados en for- } \\
\text { ma de figuras o imágenes }\end{array}$ & $\begin{array}{l}\text { 21. EL ozono-1 } \\
\text { 22. El catalizador-1 } \\
\text { 23. El catalizador-3 } \\
\text { 24. Protectores solares-4 } \\
\text { 25. La biodiversidad-1 } \\
\text { 26. La biodiversidad-2 } \\
\text { 27. Central eléctrica-1 } \\
\text { 28. Central eléctrica-3 }\end{array}$ & $\begin{array}{l}\text { 29. Perdido en el mar-1 } \\
\text { 30. Central eléctrica-2 } \\
\text { 31. Erupciones volcánicas-1 } \\
\text { 32. Extracción de aguas subterrá- } \\
\text { neas-2 } \\
\text { 33. Osmosis inversa-1 } \\
\text { 34. Malaria-1 } \\
\text { 35. La caries dental-1 }\end{array}$ \\
\hline $\begin{array}{l}\text { 4. Pruebas o datos presentados en for- } \\
\text { ma textual }\end{array}$ & $\begin{array}{l}\text { 36. Los autobuses-2 } \\
\text { 37. Las moscas-2 } \\
\text { 38. Peter Carneyl-2 } \\
\text { 39. Un riesgo para la salud-1 }\end{array}$ & $\begin{array}{l}\text { 40. El ozono-2 } \\
\text { 41. Lluvia ácida- } 2 \\
\text { 42. Brillo de Labios-2 } \\
\text { 43. Brillo de labios-3 }\end{array}$ \\
\hline $\begin{array}{l}\text { 5. Recolección de pruebas y datos y uso } \\
\text { interactivo de ítems. (Tablas) }\end{array}$ & $\begin{array}{l}\text { 44. Gafas regulables- } 2 \\
\text { 45. Casa de bajo consumo- } 5 \\
\text { 46. Gafas regulables-3 } \\
\text { 47. Gafas regulables- } 47 \\
\text { 48. Gafas regulables- } 5\end{array}$ & $\begin{array}{l}\text { 49. Correr en días de calor-1 } \\
\text { 50. Casa de bajo consumo-1 } \\
\text { 51. Casa de bajo consumo- } 2 \\
\text { 52. Casa de bajo consumo-4 }\end{array}$ \\
\hline
\end{tabular}

Esta subcompetencia está representada por 52 ítems distribuidos en las siguientes 5 categorías, generadas según las formas de presentación de las pruebas y los datos. En cada categoría se presentan, en primer lugar, un bloque de ítems abiertos los cuales involucran un mayor nivel de dificultad, puesto que requieren de la producción de una conclusión, argumento, explicación o predicción basada en los datos. Seguidamente se presentará un segundo bloque, 
donde se exponen los ítems de selección múltiple, considerados de menor exigencia debido a que se presentan unas opciones básicas, que orientan el proceso de interpretación y, por tanto, es necesario evaluar las opciones que mejor representan o explican a los datos. En la tabla 2 se exponen los ítems correspondientes a cada una de las categorías propuestas.

\section{Habilidad para interpretar pruebas o datos presentados en forma de tablas}

La interpretación de los datos, presentados en estas formas de organización de la información, ostenta el menor grado de dificultad, según los estudios de Postigo y Pozo (2000). En esta categoría se presentan 6 ejemplos de ítems PISA, cuyo proceso de análisis e interpretación, se centra en los datos dados en una tabla y que pueden ser utilizados en el aula de clase, para verificar el nivel y las diferencias existentes, con respecto a las otras categorías presentadas. En esta categoría se muestran tablas, tanto de una, como de doble entrada, y los datos presentados en la mayoría de ellas no superan un par de filas que implique un elevado manejo de datos.

En este primer bloque se presentan 4 ítems abiertos; el primero, requiere de un conocimiento de contenido, ya que es necesario manejar el tema de trasformación de energía e identificar los datos más relevantes de los presentados en las tablas, para realizar el cálculo solicitado que lleve a justificar la situación planteada (1. Chocolate-2). Se podría decir que las expresiones algebraicas o cálculos con los datos, están dentro de un nivel implícito de comprensión de la información. Sin embargo, en este caso, los cálculos realizados solo son posibles, si el estudiante ha entendido el contexto en el que se embebe el problema, de tal manera que, una vez entendido el problema, tendrá que identificar los datos pertinentes entre toda la información presentada en las dos tablas, para finalmente, justificar la idea que se plantea, en donde en cierta forma los cálculos solicitados se convierten en la explicación de dicha idea.

El siguiente ítem requiere un conocimiento procedimental, ya que es necesario el uso de los datos presentes en la tabla, generando una posible relación que justifique o dé respuesta a las preguntas planteadas (2. Combustibles fósiles-2). En este ítem, se presenta la información precisa, para evitar utilizar algún conocimiento teórico adicional sobre el tema, requiriéndose para la solución de la pregunta, un nivel de interpretación conceptual de la información mostrada en la tabla, en donde es necesario la comparación de los datos en torno al contexto de producción de energía, con lo cual se llegará a suministrar explicaciones, que den respuesta a las preguntas planteadas.

Por el contrario, el conocimiento epistémico es representado por 2 ejemplos, puesto que en ellos el análisis va más allá de la interpretación de la información, la cual requiere una comparación más minuciosa y cuidadosa de los datos presentados, tanto en forma de imágenes dentro de la tabla, como de los valores numéricos; identificando los datos que pueden justificar la teoría planteada, o cómo la variación de las proporciones que los representan puede generar un cambio de la sustancia (3. Evolución-1, 4. Brillo de labios-1).

En el primer ejemplo, se requiere un análisis comparativo de las imágenes que se presentan en la tabla, con vistas a establecer relaciones y obtener una explicación de carácter científico, que fundamente la afirmación presentada en el ítem (OECD 2006). En el segundo, un análisis detallado de los datos y pruebas presentadas, con el fin de sugerir un cambio en la receta prediciendo, cómo dicho cambio va a afectar el producto final de la sustancia en cuestión, en respuesta al planteamiento realizado. En ambos casos, se visibiliza un nivel conceptual de interpretación, requiriéndose, en el primero, una explicación; y, en el segundo, una predicción. 
Solo 2 ítems son de elección múltiple, los cuales requieren de la evaluación y selección de la opción que mejor represente o se ajuste a los datos presentados en las tablas. El primero responde a un conocimiento de contenido, ya que es necesario dentro del proceso de análisis e interpretación, el uso de conocimientos científicos sobre el tema de concentración de las sustancias y su relación con el alcance de acción, con el fin de identificar los datos que harían falta y que complementen los mostrados en el ítem para dar respuesta a la cuestión planteada (5. El maí-7). En el segundo ejemplo se utiliza un conocimiento procedimental, puesto que la pregunta lleva a una revisión de los datos presentados en la tabla, identificándose el valor de la fuente de dióxido de carbono solicitada en la pregunta y comparándola con los valores de las demás fuentes, para finalmente, evaluar y seleccionar la opción que explique mejor su posible efecto. (6. Erupciones volcánicas-3).

\section{Habilidad para interpretar pruebas o datos presentados en forma de gráficos de ejes coordenados}

Dentro de esta categoría se encuentran 14 ítems, los cuales requieren el análisis e interpretación de datos representados de forma gráfica (Osborne 2013), entendiendo la representación de las variables presentadas en la gráfica y comprendiendo los patrones que siguen (Gott y Duggan 1996). En estos ítems se presentan gráficas, principalmente de ejes coordenados o cartesianas; los datos se describen en forma de líneas, barras, columnas o puntos. Estas formas de representar los datos encierran mayor dificultad que las tablas según Postigo y Pozo (2000). Por tal motivo, estos ítems pueden servir de guía a los docentes, en los procesos de análisis e interpretación de dichas gráficas en los diferentes contextos que se presentan, o evaluar el nivel que tienen los estudiantes con respecto a las otras categorías.

Estos 14 ítems se distribuyen en dos grupos. El primero está formado por 6 ítems abiertos, que requieren la producción de una conclusión o de explicaciones que presenten una razón o argumento basados en los datos. Los ítems que precisan el conocimiento del contenido son 3. Aunque es necesario la interpretación de las gráficas visibilizando la relación entre las tres variables representadas, las respuestas finales en torno a las preguntas planteadas recaen en el uso de conceptos como los terremotos y sus efectos, la absorción y reflexión de las radiaciones solares y el conocimiento de los efectos del gas carbónico en el calentamiento global (7. El diario de Semmelweis-1, 8. Erupciones volcánicas-2 y 9. El cambio climático-1). Es decir: las respuestas de los estudiantes requieren el conocimiento de los temas mencionados anteriormente, además de la interpretación de las gráficas.

Ya en el proceso de interpretación, el primero requiere la comparación de las dos líneas de la gráfica, con el fin de identificar sus diferencias y dar una razón de cómo dichas diferencias, no sustentan el fenómeno planteado.En el segundo caso, es necesaria la comparación de tramos de una misma línea con el fin de observar las variaciones presentadas y, apoyados en el conocimiento de contenido sobre el tema, dar una explicación del fenómeno presentado. En el tercer ejemplo se requiere una comparación de las cantidades de las sustancias representadas por las barras de la gráfica, con el fin de identificar la de mayor aportación y que sumado al conocimiento teórico sobre el tema, permita generar un argumento que apoye la opinión planteada. El uso del conocimiento procedimental está representado por un solo ítem (10. Combustible fósiles-3), en el cual se presenta toda la información requerida para realizar una interpretación adecuada, sin la necesidad de recurrir a conceptos teóricos adicionales sobre el tema. De esta manera, el proceso de interpretación se centra en el análisis global de los datos, comparando las tres variables representadas en la gráfica en un formato de líneas, con el fin de generar una explicación de cómo la profundidad afecta el almacenamiento del $\mathrm{CO}_{2}$ en el mar a lo largo del tiempo, poniendo en relación la información brindada en la gráfica con el contexto que se presenta en el ítem. 
El conocimiento epistémico está representado por 2 ítems que hacen parte de una misma unidad. Estos suministran la información necesaria sobre el tema, de tal manera que el estudiante puede entender el contexto sin requerir conocimientos adicionales. A diferencia de otros, se exponen dos gráficas independientes en las cuales se representan las variables; de este modo, el ejercicio se centra en la comparación de las dos gráficas en torno al contexto presentado con el fin de generar explicaciones, justificando científicamente las conclusiones presentadas a partir de las pruebas (11. El efecto invernadero-1 y 12. El efecto invernadero-2). En el primer caso, es necesario una lectura global del comportamiento de las variables que se presentan independientemente en las gráficas, observándose cómo las tendencias de las líneas guardan una relación general al incremento; así, dicha interpretación servirá para generar la explicación que respalde la conclusión dada. El gran aporte de estos ítems subyace en el segundo caso, donde se presenta una contra conclusión, que obliga al estudiante a ser más minucioso en el análisis y a buscar sectores dentro de las gráficas, pues dicha tendencia al incremento de las variables vista inicialmente no se da. Esto permite al estudiante entender la importancia de una adecuada interpretación de los datos y de los efectos en la investigación.

En un segundo grupo, se recogen 8 ítems de selección múltiple o múltiple compleja que requieren la evaluación y selección de la opción que mejor represente o se ajuste a los datos. Dentro del conocimiento de contenido, PISA 2015 propone un ítem (13. Fumar-2), sin embargo, después de un análisis y comparación con otros ítems de la misma categoría, se plantea que este, no debería hacer parte del uso de conocimientos de contenido, puesto que su interpretación recae principalmente, en la identificación de las variables representadas y en la comprensión de la relación entre ellas, de tal manera que evoca un conocimiento principalmente procedimental, tal como lo presenta y lo utiliza Núñez et al (2009) en su investigación. En este sentido, este ítem requiere el análisis e interpretación de las tres variables presentadas en una gráfica de líneas, con el fin de comparar la tendencia de las dos líneas representativas de las variables en cuestión y analizar la relación existente, para finalmente, evaluar y seleccionar el mejor descriptor de los datos.

Otro de los ítems que también requiere un conocimiento procedimental centrado en la interpretación de una gráfica de líneas e identificación de las tres variables y la comprensión de la relación que se presenta entre ellas, conlleva una lectura global de los datos representados dentro del contexto, suministrado con el fin de analizar cuál es el efecto de la concentración de un insecticida en el despoblamiento de abejas a lo largo del tiempo y contrastándolo con la conclusión que mejor coincide con los datos de la gráfica (14. Sindrome de despoblamiento de colmenas-3). Este ítem también permite visibilizar, a partir de los datos dados en la gráfica, el uso de un grupo control que no es expuesto al insecticida y por lo tanto, se convierte en referencia de los otros dos, que utilizan una mayor concentración.

Por último, como parte del conocimiento epistémico, se tienen 6 ítems en los que la interpretación va más allá de la identificación de las variables representadas. En este tipo de ítems, el contexto juega un gran papel puesto que es necesario generar ideas a nivel argumentativo que permitan relacionar los datos presentes en las gráficas con las conclusiones que se presentan en las opciones de respuesta (15. La caries dental-3, 16. Comportamiento del espinoso-2, 17. Comportamiento del espinoso-3, 18. Cirugía con anestesia-4), o en el caso donde las pruebas dadas de forma textual, lleven a buscar la mejor relación expresada en formato gráfico y elegir la más adecuada entre varias opciones. (19. Energía eólica-1, 20. Energía eólica-2). El ítem 15 es el único ejemplo en esta competencia, que presenta una gráfica de dispersión con dos variables y puede permitir evaluar las diferencias, con respecto a los formatos clásicos de gráficas de barras y de líneas mayormente utilizados. Asimismo, las variables representadas están en función de medias de los datos, lo cual puede confundir al estudiante, ya que estos 
términos y la misma gráfica, requieren un mayor nivel de conocimientos estadísticos, lo que puede llevar a la obtención de resultados bajos.

En contraste, los tres ítems siguientes, 16,17 y 18, presentan gráficas de barras simples que son fácilmente interpretables; sin embargo, los problemas propuestos no solo requieren la interpretación de los datos presentes en la gráficas, sino también del resto de información suministrada en toda la unidad, con el fin de generar un argumento que le permita evaluar si cada una de las conclusiones presentadas son correctas o no. Finalmente, los ítems 19 y 20 presentan un formato diferente, puesto que las opciones de respuesta son varias gráficas que muestran comportamientos diferentes de las variables; por tanto, el estudiante debe centrarse en entender adecuadamente el fenómeno presentado y elegir qué comportamiento de las variables favorecería el proceso de producción de electricidad.

En esta categoría se presentan mayormente gráficas de líneas, seguidas de las gráficas de barras y, por último, una de dispersión. Principalmente, estas gráficas presentan 3 variables consideradas de mayor dificultad; sin embargo, en los casos en donde solo se muestran 2 variables que puede facilitar el análisis, se recurre a utilizar más de una gráfica o a la combinación con otro tipo de información para generar una comparación entre ellas y mantener en su mayoría el proceso de interpretación de esta categoría al mismo nivel.

\section{Habilidad para interpretar pruebas o datos presentados en figuras, imágenes y gráficas de ejes no coordenados}

En esta categoría se exponen 13 ítems que no están enmarcados dentro de los tipos más comunes y utilizados de gráficos de ejes coordenados, con los cuales los estudiantes se encuentran más familiarizados.Por lo tanto, al no tener un referente común y conocido por ellos, los gráficos e imágenes que forman parte de estos ítems pueden resultar de mayor complejidad al momento de interpretarlos. Algunos de estos presentan gráficos de sectores considerados de mayor dificultad que los de barras y líneas, según lo planteado por Postigo y Pozo (2000); aun así, esta categorización puede permitir al docente utilizarlos en diferentes actividades con el fin de valorar su nivel e identificar las dificultades que presentan sus estudiantes.

Este primer grupo integra 4 ítems abiertos que responden al uso y aplicación de un conocimiento epistémico. El primero de ellos (21. EL ozono-1) perteneció a PISA 2000 y, por ende, fue clasificado como parte del conocimiento de contenido, ya que es necesario tener claro los conceptos de átomos y moléculas; sin embargo, más allá de estos conocimientos, el ítem solicita utilizar la información brindada en las imágenes para generar un razonamiento basado en modelos, de tal manera que se tiene que hacer abstracciones con modelos que proporcionen una idea de las estructuras de los átomos y moléculas (Osborne 2013), con el fin de dar una explicación coherente a un público determinado. Asimismo, PISA 2015 propone que la comprensión de los modelos científicos, como representaciones abstractas de la ciencia, son parte del conocimiento epistémico (OECD 2016).

Los otros 3 ejemplos restantes de este primer grupo, requieren la comparación de los datos con el fin de interpretar diagramas que reproducen un contexto científico, de donde se seleccionarán las pruebas que permitan argumentar, mediante ejemplos, la idea planteada (22. El catalizador-1, 23. El catalizador-3 y 24. Protectores solares-4). En el primer caso, la comparación de las sustancias entrantes y salientes del diagrama permite detectar cuáles sufrieron un cambio según sus cantidades dadas, con lo cual se tomará cualquiera de estas sustancias como ejemplo que justifique la idea propuesta. En el segundo caso, se requiere un análisis similar para dar ejemplos de cuáles serían los problemas que se han de solucionar para hacer un sistema más eficiente y generar menor contaminación. El tercer y último ítem abierto de esta 
categoría requiere una interpretación de la información brindada en las imágenes, siendo necesario relacionarla con la información global ofrecida en la unidad a la cual pertenece este ítem, con el fin de deducir los patrones de colores adecuados, que permitan predecir apropiadamente el posible resultado que se debrá obtener en el experimento realizado.

La interpretación requerida en estos ítems va más allá de lo que presentan las figuras o diagramas, los cuales por si solos no aportarían mayor información; de tal manera que es necesario entender el contexto científico en el que se plantea cada caso, para poder evaluar la situación y llegar a generar las explicaciones adecuadas, justificándose así el uso del conocimiento epistémico.

El segundo grupo está formado por los 11 ítems restantes de selección múltiple -4 de estos necesitan conocimientos teóricos como la biodiversidad, redes tróficas y flujo de alimentos, para los dos primeros (25. La biodiversidad-1, 26. La biodiversidad-2), y conceptos de osmosis, difusión, permeabilidad, energía potencial, cinética, gravitatoria, eléctrica y funcionamiento de una turbina, en los dos siguientes, (27. Central eléctrica-1 y 28. Central eléctrica-3)-. El primer ítem requiere un nivel básico de interpretación, puesto que solo se pasa a identificar los dos animales que tienen tres fuentes de alimentación, representadas por las flechas que llegan a ellos; en cambio, el ítem siguiente ya exige una comparación entre las dos redes tróficas presentadas, con el fin de predecir en cuál de estas se vería afectado mayormente su ecosistema, si uno de los animales perteneciente a ellas desapareciera.

En los ítems sobre la central eléctrica, el proceso de interpretación se centra en entender cómo es el flujo de las moléculas dentro del diagrama y el tipo de energía que se ve involucrado en cada punto, siendo necesario tener claros los conocimientos conceptuales ya mencionados, para poder elegir la opción correcta. Los siguientes 5 ítems requieren un conocimiento procedimental, ya que es necesario el reconocimiento de las variables representadas en los gráficos e interpretar su relación. (29. Perdido en el mar-1, 30. Central eléctrica-2, 31. Erupciones volcánicas-1, 32. Extracción de aguas subterráneas-2 y 33. Osmosis inversa-1).

En el ítem 29 es esencial hacer una adecuada lectura del sistema representado, comprendiendo que el ahorro de agua es mayor debido a su circulación constante en el sistema para evitar su evaporación. En el ítem 30 tiene que relacionarse la variación de la concentración con respecto al flujo de moléculas de agua mostradas en la simulación. En este ítem se empieza a utilizar simulaciones para facilitar la visualización del fenómeno presentado, seleccionando, así, la opción que mejor se ajuste. De igual manera, el ítem de erupciones volcánicas presenta cartogramas como nuevas formas de representar los datos, en donde los mapas, de forma independiente, muestran la presencia de volcanes en ciertas zonas y los puntos donde hay mayor probabilidad de terremotos, por lo cual exigen una comparación de la información presentada en ellos, para definir el lugar donde hay menor probabilidad de un terremoto; sus respuestas son presentadas dentro de otro mapa, donde están las letras de las posibles opciones distribuidas a lo largo del mismo.

En el ítem de extracción de aguas subterráneas, se plantea una gráfica de sectores que tampoco se había visto en los ítems analizados, donde se representa los niveles de tensión en la corteza terrestres, en zonas con diferentes escalas de grises, facilitando, también, la correspondiente gama de colores para poder comparar, identificar y organizar las zonas de tensión dadas. Finalmente, el ítem 33 presenta una imagen acompañada de un texto, con toda la información requerida, con el fin de relacionar el proceso de osmosis en la membrana y decidir por dónde sale la sal en el sistema mostrado.

El conocimiento epistémico, dentro del grupo de ítems de selección múltiple, está representado por 2 de ellos, en donde es necesario ir más allá de lo que muestran las pruebas 
en las imágenes y vincular todo el contexto y la información suministrada en las opciones de respuesta. (34. Malaria-1 y 35. La caries dental11). En el primer caso, es necesario comprender cada etapa del ciclo de la malaria indicado en la imagen y pasar a identificar cuáles se verán afectadas, según el método utilizado para impedir su propagación. El formato de opción múltiple compleja, permite presentar varios métodos y, en cada uno, señalar qué etapas se verán afectadas, llevando al estudiante a una constante interrogación que requiere de una visión global del problema, permitiendo una interpretación adecuada y la selección de las opciones correctas. El ítem de caries dental-1 exige, igualmente, una comparación de toda la información brindada entre el texto, la imagen y las opciones de respuesta, lo cual va más allá de un análisis procedimental, basado en la información que solo brinda la gráfica a uno espistémico, en donde las explicaciones y argumentos solo se generan bajo la comprensión global del contexto.

En esta categoría, la mayor parte de los ítems presentan imágenes, dentro de las cuales se suministra las pruebas y solo en uno se visibiliza una gráfica de sectores, siendo este tipo un formato nuevo dentro de los ítems analizados, al igual que los mapas como medios de representación de datos. También es importante destacar que la mayoría de los ítems son estáticos y solo en aquellos que fueron liberados, como ejemplos de las pruebas PISA 2015, se empiezan a presentar formatos interactivos mediante simulaciones, los cuales pueden generar un mayor interés, tanto en los profesores como en los estudiantes.

\section{Habilidad para interpretar pruebas o datos presentados en forma textual}

En esta categoría se presentan 8 ítems estructurados en formatos textuales, dentro de los cuales se presentan las pruebas necesarias que el estudiante debe identificar e interpretar para su solución. En los estudios de Postigo y Pozo (2000), se ha encontrado que las pruebas dadas en este tipo de formato tiende a presentar un mayor nivel de dificultad con diferencias estadísticamente significativas, en comparación a cualquiera de las categorías trabajadas anteriormente. Por tal motivo, se ha creado esta, en donde se presentan 8 ítem que pueden ser utilizados por los docentes, para generar comparaciones entre los diferentes formatos presentados.

En primer lugar, tenemos un grupo de 4 ítems en forma de preguntas abiertas donde se tendrá que elaborar una conclusión, razón o argumento válido, que dé cuenta de una adecuada interpretación de las pruebas o datos. De estos ítems, 3 corresponden a un conocimiento de contenido, pues es necesario manejar conceptos como contaminación, productos de combustión, funcionamiento de motores diésel y eléctricos, resistencia a sustancias, trasmisión genética, velocidad y distancia de detención de los vehículos (36. Los autobuses-2, 37. Las moscas2 y 38. Peter Carneyl-2). En el primer caso, se utilizarán dichos conocimientos para evaluar una conclusión dada y dar razones a favor o en contra de esta. En el segundo caso, el estudiante tendrá que dar una conclusión alternativa a la presentada, justificando el porqué se está generando el fenómeno expuesto. En el tercer caso, se darán razones a favor y en contra de una decisión tomada, sustentando cómo las nuevas posiciones benefician una mejor velocidad, pero, al mismo tiempo, puede afectar la reacción de los vehículos en situación de frenado.

En todos ellos se solicita generar conclusiones o explicaciones, a partir de las pruebas presentadas como parte del nivel de interpretación conceptual. Un solo ítem corresponde al uso del conocimiento procedimental, que implica evaluar y cuestionar un procedimiento experimental, en donde se pone en duda la veracidad de una conclusión a partir del tipo de mediciones realizadas, (39. Un riesgo para la salud-1). El estudiante tendrá que dar una razón que confirme la idea planteada, demostrando su capacidad de emitir juicios sobre la relevancia del asunto, la idoneidad y credibilidad de dicha información (OECD 2006). Este ítem es uno de 
los pocos ejemplos en donde se alcanza el cuarto nivel de interpretación o de lectura, detrás de los datos (Friel et al. 2001), debido a ese cuestionamiento de las pruebas y de la metodología utilizada.

En un segundo grupo se recogen los 4 ítems basados en preguntas de elección múltiple o múltiple compleja. Se evaluará la mejor conclusión, razón o argumento de una lista, pasándose a elegir la que mejor representa a los datos o pruebas científicas. De 4 ejemplos presentados, 2 apuntan principalmente a un conocimiento de contenido (40. El ozono-2, 41. Lluvia ácida-2). En el primer caso, la comprensión de conceptos como ozono, troposfera, estratosfera y tormentas eléctricas, facilitarán la relación entre el concepto que se presenta y la definición adecuada. En el segundo caso, conceptos sobre reacciones químicas, carbonatos, acidez, solubilidad y pérdida de masa, son necesarios para la selección de la mejor predicción de la situación expuesta. Los dos ítems restantes requieren de un conocimiento epistémico (42. Brillo de Labios-2, 43. Brillo de labios-3), ya que en ellos se da la información necesaria para que el estudiante relacione dichas pruebas con la pregunta planteada con el fin de generar predicciones o inferencias, en este caso, sobre los posibles efectos que pueden causar las sustancias mencionadas, exigiendo una lectura más allá de los datos en los niveles de Curcio (1989).

En ellos se evalúan los efectos de los procedimientos realizados, prediciendo qué puede causar el agregar un exceso de agua en la mezcla, en el primer caso, o prediciendo el comportamiento del jabón en presencia de los otros reactivos; para el segundo caso, situaciones presentadas en contextos experimentalmente prácticos y que no requieren del uso de conceptos extras para su solución.

\section{Habilidad para recolectar pruebas o datos y uso interactivo del Ítem.}

Esta última categoría es, tal vez, la más compleja de todas las presentadas anteriormente en esta subcompetencia, puesto que no solo se centra en el análisis e interpretación de los datos o pruebas dadas, sino que es necesario sumar un paso adicional, que en ninguno de los ítems de las anteriores categorías se había visto: la recolección de esos datos o pruebas a partir de la manipulación de las diferentes condiciones proporcionadas en el simulador y que pasan a sistematizarse, principalmente, en forma de tablas, las cuales se analizarán e interpretarán para dar respuesta al problema propuesto en cada uno de ellos. Los ítems de esta categoría tienen una interfaz dinámica, solo en PISA 2015, donde el estudiante precisa entender el simulador y el manejo de los controles, que va asociado a un fenómeno y sus variables. Según la prueba, se variarán las condiciones iniciales para la recolección de datos y su interpretación, por lo que se puede permitir observar cuál es el rendimiento de los estudiantes en comparación con los ítems tradicionales y las diferencias y dificultades que se pueden presentar.

En esta categoría se presentan 9 ítems con formato de selección múltiple, de los cuales dos requieren de un conocimiento de contenido (44. Gafas regulables-2 y 45. Casa de bajo consumo-5). En el primer caso, es necesario un conocimiento básico sobre volumen y cómo afecta la variación de la cantidad de líquido en la forma de una lente, siendo necesario manipular el control que permite variar la cantidad de fluido a extraer, o añadir y observar los cambios que se generan en la imagen dinámica. Este ítem no presenta mayor dificultad y es un ejercicio introductorio a otros de la misma unidad, que requieren procesos más complejos. En el segundo caso, es preciso conocer cómo afecta el color a la absorción y reflexión de la energía, con el fin de relacionar las variables de temperatura exterior y el consumo de energía de una casa, según el color del tejado. Esta prueba evalúa el conocimiento del contenido en mayor proporción que el procedimental, aunque es necesaria la recolección de los datos para la selección de la respuesta final. 
Los 7 ítems restantes requieren del conocimiento procedimental, centrado en la recolección de los datos y el análisis e interpretación de estos, que conlleven a la selección de la opción que mejor los represente. Así, los tres ítems 46. Gafas regulables-3, 47. Gafas regulables-4 y 48. Gafas regulables-5, exponen toda la información requerida para el estudiante: desde las instrucciones para utilizar el simulador, hasta el contexto en el cual se desenvuelve, siendo necesario que el alumno ajuste las condiciones requeridas, obtenga los datos y en función de los mismos, responda cómo afecta la regulación del volumen de las gafas a la visión de los tres discentes. De igual manera el ítem 49. Correr en días de calor-1 requiere la variación de las condiciones de temperatura, humedad del aire y consumo o no de agua, para identificar si las condiciones dadas pueden afectar a la salud de un corredor. Finalmente los ítems 50. Casa de bajo consumo-1, 51. Casa de bajo consumo-2 y 52. Casa de bajo consumo-4 permiten entender cómo las variables de temperatura exterior y color de tejado afectan el consumo de energía de la casa a partir de los datos recolectados.

\section{Conclusiones}

La competencia Interpretar Datos o Pruebas Cientificas está representada por 52 ítems. 18 ítems constituyen preguntas abiertas y conducen a una conclusión, explicación o predicción en torno a los datos presentados, requiriéndose en muchos de ellos, el aporte de pruebas basadas en estos, para estar a favor o en contra de una conclusión, o la propuesta de conclusiones alternativas a la ya presentada; además, estos ítems permiten analizar la capacidad de los estudiantes, para comunicar y argumentar. Un solo ítem (Comportamiento del espinoso-3) tiene un formato de pregunta cerrada construida, en donde las respuestas no son abiertas en su totalidad, pues están definidas por el ordenamiento de las gráficas presentadas. Los 33 ítems restantes implican la evaluación y selección de la opción que mejor represente los datos, siendo 29 de elección múltiple y 4 de elección múltiple compleja.

Con base en lo anterior, el docente presenta un gran número de ejemplos tanto para evaluar la capacidad de proponer conclusiones o argumentos con los ítems abiertos, los cuáles además, permitirán analizar en detalle, qué tipo de conclusiones generan los estudiantes y qué dificultades tienen en su redacción o, también puede utilizar los ítems de elección múltiple, lo que daría una idea inicial de que tan capaces son los estudiantes de elegir la mejor conclusión. Estos ítems son una herramienta puesta al servicio de los docentes, que pueden ayudar a entender mejor a sus estudiantes y mejorar sus prácticas educativas.

Del total de los ítems, solo uno permite cuestionar el método experimental que se utilizó y más aún, permite el cuestionamiento del proceso de investigación (Un riesgo para la salud-1), ya que solicita una razón que lleve a dudar en torno a las declaraciones hechas por los científicos. Este ítem requiere una mirada crítica de los datos y, por tanto, sugiere un nivel de lectura detrás de los mismos en los términos de Friel et al. (2001). Aunque en el marco teórico de PISA 2006 (OECD 2006), se menciona que el ítem fue descartado del estudio, debido a las diferencias entre los resultados de los países que participaron, también menciona la incomodidad del comité científico, ya que algunas respuestas cuestionaban la honestidad de la investigación científica. Se considera importante discutir este último hecho constantemente en clase, puesto que es necesario ese cuestionamiento de la ciencia, ya que a través de la historia y más aún en el presente, la investigación científica se ha visto envuelta en contradicciones, debido a investigaciones sesgadas hechas por científicos que tienen intereses particulares y llevan a favorecer un concepto inadecuado. Este ítem puede ser un ejemplo claro que permita al maestro, relacionar situaciones semejantes dadas en sus contextos y que puedan ser discutidas en clase. 
Con respecto al tipo de conocimiento, se distinguen 3 grupos de ítems. Un primer grupo de 16 ítems, que responden a un conocimiento de contenido, requiriéndose de conceptos clave para dar respuesta a las preguntas. Un segundo grupo de 18 ítems, ligados a un conocimiento procedimental, centrado principalmente en el reconocimiento de las variables y la relación entre estas dentro de tablas, gráficos o figuras. Y un tercer grupo de 18 ítems, que requieren de un conocimiento epistémico, el cual está relacionado con las explicaciones que se generan con respecto al mundo natural, relacionando los datos dados, el contexto presentado y la información aportada a mayores de las tablas o gráficas. En relación con elconocimiento epistémico, PISA concede importancia a la naturaleza del razonamiento utilizado para interpretar las pruebas y los datos, deduciendo la respuesta o seleccionando la inferencia a la mejor explicación de los datos o pruebas proporcionadas (OECD 2016). Siendo esta clasificación con base en los conocimientos, ejemplos claros para que los docentes comprendan cuál de ellos está evaluando, en dónde se presentan mayores dificultades y qué pueden hacer para mejorar sus resultados.

Del total de ítems analizados en este trabajo, 43 de ellos han sido propuestos en la pruebas PISA de 2000 a 2012 y se consideran de carácter estáticos, ya que se presentan de forma que solo se requiere un análisis o interpretación. Los 9 últimos ítems solo han sido propuestos en las recientes pruebas PISA 2015 y tienen un carácter dinámico, donde solo uno, Central eléctrica azul-2 utiliza una imagen con animación, para que el estudiante deduzca el proceso que se presenta. Los 8 ítems restantes se muestran como simulaciones, donde es necesario que el estudiante interactúe con los controles que permiten el cambio de las variables, para obtener los datos requeridos, dotándoles de una capacidad heurística, en términos de Gallardo (2010), puesto que es necesario que el alumno diseñe un plan que le permita seguir los pasos necesarios para llegar a la solución. Estos últimos ítems pueden dar luces al docente de qué tan capacitados están sus estudiantes, en el proceso mismo de selección de variables para recoger unos datos adecuados, seleccionar los datos que mejor convengan para el análisis y generar una interpretación lógica que lleven a la construcción de conclusiones apropiadas.

Teniendo en cuenta la categorización que se realiza en este trabajo, es evidente la importancia que se da a la forma como se presentan los datos, pues los estudiantes deben ser capaces de leer cualquiera de estas formar de representación. Sin embargo, el proceso gráfico ha sido un tema delegado al área de matemáticas, por lo cual se presta menor atención desde las ciencias, tal como lo enuncia Arias et al. (2011) quienes al analizar diferentes textos de ciencias, principalmente de la Editorial Santillana, encuentran que el uso de gráficas no supera el 10\% en relación a las páginas del libro, reconociendo que es muy importante el aprendizaje de estos temas desde varias áreas y más aún desde las ciencias, puesto que la habilidad de manejar la información a partir de gráficas suele ir acompañada de contextos reales, en donde frecuentemente se usan con fines comunicativos, usos importantes en este mundo moderno, donde las diferentes áreas del conocimiento utilizan múltiples formas de representación de los datos, como método de comunicación y que cualquier persona debería leer e interpretar con facilidad.

La subcompetencia Interpretar datos y pruebas cientificas, requiere, por tanto, un manejo procedimental derivado del trabajo en la elaboración e interpretación de las diferentes maneras de representación de los datos, siendo necesario que el docente de ciencias utilice estas formas de manera constante en el aula, llevando siempre a los estudiantes, y desde diferentes temas, al trabajo con los datos y construcción de estos diferentes modelos de representarlos. También los ítems trabajados dan ideas de cómo se pueden organizar los datos y qué debemos solicitar al estudiante, para que realice un proceso sistemático y adecuado de interpretación y producción de las respectivas conclusiones. 
El comprender en que consiste cada una de las subcompetencias científicas, nos lleva a evaluar de mejor manera los resultados que presenta las pruebas internacionales PISA, de tal manera que, según los resultados obtenidos por subescalas o subcompetencias, un determinado país sabría en donde se debe de generar cambios específicos, para que dicha subcompetencia este al nivel de las demás.

Para finalizar, conviene señalar que este estudio de categorización de los ítems y la comprensión de las subcompetencias y conocimientos estudiados hasta el momento, tienen como fin una aplicación práctica con un grupo de estudiantes, en donde, mediante un proceso de evaluación diagnóstica, se analizarán sus debilidades en cuanto a los conocimientos y subcompetencias descritas. Este hecho hace que nos, centremos, principalmente, en las habilidades específicas ya mencionadas, con el fin de intervenir en el aula a partir de la generación y aplicación de unidades didácticas, centradas en desarrollar las habilidades con mayor dificultad. De esta manera, si conocemos cuáles son las necesidades de nuestros estudiantes, sabremos qué debemos hacer como docentes para ayudarlos.

\section{Referencias bibliográficas}

Arias Hernández C., Leal L. H., Organista Rodríguez M. L. (2011) La Modelización de la Variación, un análisis del uso de las Gráficas Cartesianas en los Libros de Texto de Biología, Física y Química de Secundaria. Revista de Ciencias 15, 93-128.

Baquero B., Schnotz W., Reuter S. (2000) Adolescents' and adults' skills to visually communicate knowledge with graphics. Infancia y Aprendizaje. Journal for the Study of Education and Development, 71-87.

Berciano A., Ortega T., Puerta M. (2015) Aprendizajes de las Interpolaciones gráficas y algebraicas. Análisis comparativo. Enseñanza de las Ciencias 33(3), 43-58.

Bravo B., Puig B., Jiménez-Aleixandre M. P. (2009) Competencias en el uso de pruebas en argumentación. Educación química, 137-142.

Bybee R. W. (1997) Achieving Scientific Literacy: From Purposes to Practices. Westport. CT 06881: Heinemann, 88 Post Road West, PO Box 5007.

Carswell C. M., Emery C., Lonon A. M. (1993) Stimulus Complexity and Information integration in the Spontaneous Interpretations of Line Graphs. Applied Cognitive Psychology 7, 341-357.

Curcio F. R. (1989) Developing Graph Comprehension. Elementary and Middle School Activities. Consejo Nacional de Profesores de Matemáticas, Inc., 1906 Asociación Drive, Reston, VA 22091.

De Pro B. A. (1998) ¿Se puede enseñar contenidos procedimentales en las clases de ciencias? Enseñanza de las Ciencias 16 (1), 21-41.

Friel S. N., Curcio F. R., Bright G. W. (2001) Making Sense of Graphs: Critical Factors Influencing Comprehension and Instructional Implications. Journal for Research in Mathematics Education 32 (2), 124-158.

Gallardo-Gil M., Fernández-Navas M., Sepúlveda-Ruiz M.-P., Serván M.-J., Yus R., Barquín J. (2010) PISA y la Competencia Científica: Un análisis de las pruebas de PISA en el Área de las ciencias. RELIEVE 16 (2), 1-17.

García J. J., Palacios F. J. (2007) ¿Comprenden los Estudiantes las Gráficas Cartesianas usadas en los Textos de Ciencias? Investigación Didáctica 25(1), 107-132. 
Gott R., Duggan S. (1996) Practical work: its role in the understanding of evidence in science. International Journal of Science Education 18(7), 791-806.

Leinhardt G., Zaslavsky O., Stein M. K. (1990) Graphs and Graphing: Tasks, Learning, and Teaching. Review of Educational Research 60(1), 1-64.

Muñoz J., Charro E. (2017) Los ítems PISA como herramienta para el docente en la identificación de los conocimientos y habilidades científicas. Revista Eureka sobre Enseñanza y Divulgación de las Ciencias 14(2), 317-338.

National Research Council (2012) A Framewor for K-12 Science Education Practices, Crosscutting Concepts, and Core Ideas. Washington, D.C.: The National Academies Press.

Nuñez F., Hernández E. B., Aranda R. C. (2009) Capacidad del Alumnado de Educación Secundaria Obligatoria para la Elaboración e Interpretación de Gráficas. Enseñanza de las Ciencias 27 (3), 447-462.

OECD (2006) PISA 2006. Marco de la Evaluación. Conocimientos y habilidades en Ciencias, Matemáticas y Lectura. Paris: OECD Publishing.

OECD (2016) PISA 2015 Assessment and Analytical Framework: Science, Reading, Mathematic and Financial Literacy. Paris: OECD Publishing.

OECD (2017) Programme for International Student Assessment. Obtenido de Programme for International Student Assessment: http://www.oecd.org/pisa/data/

Osborne J. (2013) The 21st century challenge for science education: Assessing scientific reasoning. Thinking Skills and Creativity 10, 265-279.

Perales F. J., Vilchez J. M. (2015) Iniciación de la Investigación educativa con estudiantes de secundaria: el papel de las ilustraciones en los libros de texto de ciencias. Enseñanza de las Ciencias 33(1), 243-262.

Postigo Y., Pozo J. I. (2000) Cuando una gráfica vale más que 1.000 datos: la interpretación de gráficas por alumnos adolescentes. Infancia y Aprendizaje. Journal for the Study of Education and Development, 89-110.

Schalk H. H., Schee J. A., Boersma K. T. (2008) The use of concepts of evidence by students in Biology investigation: Development Research in Pre-Unieversity Education. Paper presented at the 7th ERIDOB Conference (págs. 1-12). Netherlands: Uthecht University.

Smith K. C., Nakhkeh M. B., Bretz S. L. (2010) An expanded framework for analyzing general chemistry exams. Chemistry Education Research and Practice 11, 147-153.

Solar H., Deulofeu J., Azcárate C. (2015) Competencia de la modelización en interpretación de gráficas funcionales. Enseñanza de las Ciencias, 33(2), 191-210.

Swan M., Phillips R. (1998) Graph interpretation skill among lower-achieving school leavers. Research in Education 60, 10-20.

UNEP (2012) 21 Issues for the 21st Century: Result of the UNEP Foresight Process on Emerging Environmental Issues. United Nations Environment Programme (UNEP): Nairobi, Kenya. 


\section{Anexo A}

Habilidad específica 1: Interpretar datos dados en forma de tabla.

\section{Chocolate-2}

En un libro en el que se habla de valores nutricionales se mencionan los siguientes datos acerca del chocolate, Supón que todos estos datos son aplicables al tipo de chocolate que come, frecuentemente, Jessica. También, considera que cada barrita de chocolate que come tiene un peso de 100 gramos.

Tabla I

Contenido nutritivo de $100 \mathrm{~g}$ de chocolate

\begin{tabular}{|c|c|c|c|c|c|c|c|c|}
\hline $\begin{array}{c}\text { Proteína } \\
\text { s }\end{array}$ & Grasas & $\begin{array}{c}\text { Hidratos } \\
\text { de } \\
\text { Carbono }\end{array}$ & \multicolumn{2}{|c|}{ Minerales } & \multicolumn{3}{|c|}{ Vitaminas } & $\begin{array}{c}\text { Energía } \\
\text { Total }\end{array}$ \\
\hline & & & Calcio & Hierro & A & B & C & \\
\hline $5 \mathrm{~g}$ & $32 \mathrm{~g}$ & $51 \mathrm{~g}$ & $50 \mathrm{mg}$ & $4 \mathrm{mg}$ & - & $0,20 \mathrm{mg}$ & - & $2142 \mathrm{~kJ}$ \\
\hline
\end{tabular}

Según los datos de la tabla 100 gramos de chocolate contienen 32 gramos de grasas y proporcionan $2142 \mathrm{~kJ}$ de energía. La nutricionista afirmó: «Las grasas le proporcionan la energía para vivir...»

La tabla II, muestra la cantidad diaria recomendada de nutrientes y de kilojoules para una mujer de actividad normal.

El artículo dice que la dieta de Jessica consiste en 90 barras de chocolate por semana, pero que ella mantiene su peso estable. Supón que las barras de chocolate que ella come pesan 100 gramos cada una. De los datos de las tablas I y II puedes calcular que es difícil creer que Jessica mantenga su peso con esta dieta.

Muestra esto por medio de un cálculo.

Respuesta:

\section{Tabla II}

Cantidad diaria recomendada de nutrientes y de kilojoules de energía

\begin{tabular}{|c|c|c|c|c|c|c|c|c|c|c|c|}
\hline Fila & $\begin{array}{c}\text { Edad } \\
(\mathrm{años})\end{array}$ & $\begin{array}{c}\text { Peso } \\
(\mathrm{kg})\end{array}$ & $\begin{array}{c}\text { Proteínas } \\
(\mathrm{g})\end{array}$ & $\begin{array}{c}\text { Grasas } \\
(\mathrm{g})\end{array}$ & $\begin{array}{c}\text { Carbo- } \\
\text { hidratos } \\
(\mathrm{g})\end{array}$ & \multicolumn{2}{|c|}{ Minerales } & \multicolumn{3}{|c|}{ Vitaminas } & $\begin{array}{c}\text { Energía } \\
\text { total }\end{array}$ \\
\hline & & & & & & Calcio & $\begin{array}{c}\text { Hierro } \\
(\mathrm{mg})\end{array}$ & $\begin{array}{c}\mathrm{A} \\
(\mathrm{mg})\end{array}$ & $\begin{array}{c}\mathrm{B} \\
(\mathrm{mg})\end{array}$ & $\begin{array}{c}\mathrm{C} \\
(\mathrm{mg})\end{array}$ & $\begin{array}{c}(\mathrm{kJ}) \\
(\mathrm{mg})\end{array}$ \\
\hline 1 & $16-19$ & 50 & 60 & 85 & 320 & 0.9 & 15 & 0.45 & 2.5 & 50 & 9180 \\
\hline 2 & $16-19$ & 60 & 60 & 90 & 350 & 1.0 & 15 & 0.45 & 2.5 & 75 & 9660 \\
\hline 3 & $20-35$ & 50 & 60 & 80 & 300 & 0.7 & 12 & 0.45 & 2.3 & 40 & 8990 \\
\hline 4 & $20-35$ & 60 & 60 & 85 & 330 & 0.8 & 12 & 0.45 & 2.4 & 50 & 9240 \\
\hline
\end{tabular}

